\title{
Corynebacterium coyleae as potential urinary tract pathogen
}

\author{
Beata Sokol-Leszczynska ${ }^{1,2} \cdot$ Piotr Leszczynski ${ }^{1,3} \cdot$ Dominika Lachowicz $^{2} \cdot$ Olga Rostkowska $^{4} \cdot$ Mariusz Niemczyk $^{5}$. \\ Tomasz Piecha $^{6}$ - Alex van Belkum ${ }^{7}$ - Anna Sawicka-Grzelak ${ }^{2}$. Grazyna Mlynarczyk ${ }^{1,2}$
}

Received: 1 April 2019 / Accepted: 2 April 2019 / Published online: 27 April 2019

(C) The Author(s) 2019

\begin{abstract}
Corynebacterium coyleae is part of the commensal microflora of the skin, urethra, mucous membranes, and genital tract. Isolates from patients with urinary tract infection (UTI) were reported, but the pathogenic potential of this species has not been defined yet. The aim of the study is to determine whether $C$. coyleae could be the etiological agent of UTI and to analyze its antibiotic susceptibility. Urine samples were cultured quantitatively according to accepted laboratory procedures. The identification of bacterial isolates was carried out using the Vitek MS (bioMérieux) and antibiotic susceptibility was tested using disc diffusion according to EUCAST guidelines. Between 1 January 2017 and 30 October 2018, a total of 39 C. coyleae strains were isolated. This represented $0.32 \%$ of all urine samples cultured in the laboratory during the collection period. The strains were isolated from samples obtained from 35 women and 3 men (age median for all -64 years). One female patient presented with C. coyleae in her urine twice at an interval of 21 months. In six cases of UTI, C. coyleae was isolated in monoculture. The isolates had the same resistance pattern. A total of 11 strains were obtained from cases with a clinical diagnosis of UTI. In 13 cases, the strain was cultured in a monoculture and in 28 cases with accompanying species. All strains were susceptible to vancomycin. However, resistance to ciprofloxacin was observed for $58.4 \%$ of the strains. Urine isolates of $C$. coyleae must be considered as contamination or normal flora in most cases $(28 / 39,72 \%)$. In the remaining cases, it can be considered as potential etiologic agents, mostly in women and especially in the 6 UTI cases where C. coyleae was found as the single culture-positive species. Several of these isolates demonstrate resistance to antibiotics commonly used in empiric treatment of urinary tract infections.
\end{abstract}

Keywords Corynebacterium coyleae $\cdot$ Urinary tract infection $\cdot$ Microflora $\cdot$ Antimicrobial susceptibility

Piotr Leszczynski

piotr.leszczynski@wum.edu.pl

1 Department of Medical Microbiology, Medical University of Warsaw, Warsaw, Poland

2 Department of Medical Microbiology, University Medical Center, Hospital of the Infant Jesus, Warsaw, Poland

3 Infection Control Team, University Medical Center, Hospital of the Infant Jesus, Warsaw, Poland

4 Department of Transplantation Medicine, Nephrology and Internal Medicine, Medical University of Warsaw, Warsaw, Poland

5 Department of Immunology, Transplant Medicine and Internal Diseases, Medical University of Warsaw, Warsaw, Poland

6 Department of General Oncological and Functional Urology, Medical University of Warsaw, Warsaw, Poland

7 BioMérieux, R\&D Microbiologie, Route de Port Michaud, 38390 La Balme les Grottes, France

\section{Introduction}

Corynebacterium coyleae was isolated for the first time in 1997 by Funke et al. [1] from the blood cultures of six patients with episodes of fever of unknown origin; one patient was infected with the human immunodeficiency virus (HIV), whereas the other five patients had a previous surgical intervention as the underlying condition. Furthermore, C. coyleae has been recovered from a definite sepsis case, probable case of sepsis and soft tissue infection, and possible post-transfusion bacteremia, neonatal bacteremia [2], pancreatic abscesses mimicking malignant neoplasm [3], burn injuries [4], pleural fluid specimens [1, 5], abscesses [6], and ulcers [7]. Still, there is ongoing controversy on its official pathogen status.

Resistance to beta-lactam antibiotics has not commonly been described in $C$. coyleae isolates. All isolates tested by Fernandez et al. [2] were susceptible to $\beta$-lactams, gentamicin, rifampin, tetracycline, vancomycin, linezolid, and 
resistant to clindamycin. Isolates from hospitalized patients reported by Barberis et al. [5] demonstrated a significantly higher resistance rate to antibiotics than those from outpatients. The aim of the current study is to determine whether C. coyleae could be an etiological agent of urinary tract infections and to analyze its antibiotic susceptibility.

\section{Material and methods}

The retrospective analysis included urine cultures performed in 2017 (January 1st-December 31st) and in 2018 (January 1 st-October 31 st). The samples were taken from in- and outpatients. The patients were aged 21-90 (arithmetic mean62 years, midrange -55 years, median -64 years). Urine samples were cultured quantitatively according to the laboratory's procedures. Middle stream urine (MSU) samples from women after transplantation and catheterized samples (CS) were cultured with $10 \mu$ l loop on CPS medium (bioMerieux, France); samples from men were cultured with $1 \mu \mathrm{lloop}$; and $100 \mu \mathrm{l}$ samples from percutaneous nephrostomy and samples taken directly from renal pelvis were cultured. CPS and McConkey were applied for MSU, and CS were additionally cultured on blood agar and Schoedler's medium (bioMerieux, France). The samples were incubated in $37^{\circ} \mathrm{C}$ for $18-24 \mathrm{~h}$. The identification was initially based on the colony and cell morphology, and then carried out in the Vitek MS (bioMérieux, France). VITEK MS is an adequate tool for the identification of C. coyleae. Although the database only contains 37 spectra obtained for 9 strains, it is 97.3\% accurate and does not provide incorrect identifications (no discordances). Due to the small size of C. coyleae

Table 1 Bacterial isolates accompanying C. coyleae from 11 patients with suspected UTI

\begin{tabular}{lll}
\hline Patient & \multicolumn{2}{l}{ Isolates } \\
\cline { 2 - 3 } & $\begin{array}{l}\text { C. coyleae } \\
\text { Bacteriuria }(\mathrm{cfu} / \mathrm{ml})\end{array}$ & Accompanying species \\
\hline 1 & $10^{3}$ & None \\
2 & $10^{3}$ & \\
3 & $10^{4}$ & \\
4 & $10^{4}$ & \\
5 & $10^{4}$ & \\
6 & $10^{4}$ & E. faecalis $\left(10^{3}\right)$ \\
7 & $10^{4}$ & E. faecalis $\left(10^{3}\right)$ \\
8 & $10^{4}$ & E. faecalis $\left(10^{5}\right)$ \\
9 & $10^{4}$ & E. coli $\left(10^{2}\right)$ \\
10 & $10^{3}$ & E. coli $\left(10^{4}\right)$ \\
\hline
\end{tabular}

Table 2 C. coyleae isolates from non-UTI (control) 28 cases

\begin{tabular}{|c|c|c|}
\hline \multirow[t]{2}{*}{ Patient } & \multicolumn{2}{|l|}{ Isolates } \\
\hline & $\begin{array}{l}\text { C. coyleae } \\
\text { Bacteriuria (cfu/ml) }\end{array}$ & Accompanying species \\
\hline 1 & $10^{2 *}$ & None \\
\hline 2 & $10^{3}$ & \\
\hline 3 & $10^{3}$ & \\
\hline 4 & $10^{3}$ & \\
\hline 5 & $10^{4}$ & \\
\hline 6 & $10^{4}$ & \\
\hline 7 & $10^{4}$ & \\
\hline 8 & $10^{4}$ & \\
\hline 9 & $10^{4}$ & \\
\hline 10 & $10^{5}$ & \\
\hline 11 & $10^{5}$ & \\
\hline 12 & $10^{4}$ & \\
\hline 13 & $10^{4}$ & \\
\hline 14 & $10^{4}$ & \\
\hline 15 & $10^{3}$ & P. mirabilis $\left(10^{3}\right)$ \\
\hline 16 & $10^{4}$ & E. faecalis $\left(10^{3}\right)$ \\
\hline 17 & $10^{4}$ & E. faecalis $\left(10^{3}\right)$ \\
\hline 18 & $10^{4}$ & S. epidermidis $\left(10^{4}\right)$ \\
\hline 19 & $10^{4}$ & S. saprophyticus $\left(10^{4}\right)$ \\
\hline 20 & $10^{4}$ & E. $\operatorname{coli}\left(10^{5}\right)$ \\
\hline 21 & $10^{4}$ & P. vulgaris $\left(10^{5}\right)$ \\
\hline 22 & $10^{5}$ & S. hominis $\left(10^{4}\right)$ \\
\hline 23 & $10^{3}$ (predominant) & E. coli $\left(10^{3}\right)+$ C. albicans $\left(10^{4}\right)$ \\
\hline 24 & $10^{5}$ & E. $\operatorname{coli}\left(10^{3}\right)$ \\
\hline 25 & $10^{3}$ & S. haemolyticus $\left(10^{3}\right)$ \\
\hline 26 & $10^{3}$ & E. faecalis $\left(10^{4}\right)$ \\
\hline 27 & $10^{4}$ & E. faecalis $\left(10^{4}\right)$ \\
\hline 28 & $10^{5}$ & S. agalactiae $\left(10^{4}\right)$ \\
\hline
\end{tabular}

*- urine obtained by catheterization

colonies, circa 5-10 colonies were applied on the MALDI sample slide. The susceptibility was tested with the disc diffusion method according to EUCAST guidelines and standardized laboratory procedures.

\section{Results}

A total number of 39 strains were isolated, representing $0.32 \%$ of all urine cultures during this period. Thirty-six strains were from women and three from men. In case of one female (73 years), C. coyleae was isolated twice at an interval of 21 months. In 2017, seven strains were cultured from patients with UTI symptoms; in three cases as a monoculture $\left(10^{4} \mathrm{cfu} /\right.$ 
Table 3 Bacterial strains isolated from urine samples taken from two patients

\begin{tabular}{|c|c|c|}
\hline Patient & Urine sample & Isolates/bacteriuria $(\mathrm{cfu} / \mathrm{ml})$ \\
\hline \multirow[t]{2}{*}{$\begin{array}{l}\text { Female, } 73 \\
\text { years, UTI }\end{array}$} & Middle stream urine & $\begin{array}{l}\text { C. coyleae }\left(10^{4}\right) \\
\text { E. coli }\left(10^{5}\right)\end{array}$ \\
\hline & Nephrostomy & E. $\operatorname{coli}\left(10^{2}\right)$ \\
\hline \multirow[t]{2}{*}{$\begin{array}{l}\text { Female, } 26 \text { years, } \\
\text { UTI susp. }\end{array}$} & $\begin{array}{l}\text { Nephrostomy } \\
\quad \text { (pyonephrosis) }\end{array}$ & $\begin{array}{l}\text { C. coyleae }\left(10^{3}\right) \\
\text { P. mirabilis }\left(10^{3}\right) \\
\text { S. epidermidis }\left(10^{3}\right) \\
\text { Prevotella spp. }\left(10^{5}\right) \\
\text { P. assacharolyticus }\left(10^{5}\right) \\
\text { Lactobacillus spp. }\left(10^{5}\right)\end{array}$ \\
\hline & $\begin{array}{l}\text { Nephrostomy } \\
\text { (sample obtained } \\
3 \text { days later) }\end{array}$ & P. mirabilis $\left(10^{5}\right)$ \\
\hline
\end{tabular}

$\mathrm{ml})$; in 3 cases together with Enterococcus faecalis $\left(10^{3} \mathrm{cfu} /\right.$ $\mathrm{ml}$ twice, $10^{5} \mathrm{cfu} / \mathrm{ml}$ once); and in one case with $E$. coli $\left(10^{4} \mathrm{cfu} / \mathrm{ml}\right) ; 17$ strains were cultured from non-UTI patients; in 9 cases as monoculture (twice $10^{5} \mathrm{cfu} / \mathrm{ml}$, fivefold $10^{4} \mathrm{cfu} /$ $\mathrm{ml}$, once $10^{3} \mathrm{cfu} / \mathrm{ml}$ and once $10^{2} \mathrm{cfu} / \mathrm{ml}$ ). In 2018, 4 strains were cultured from patients with UTI symptoms cases; in 3 cases as monoculture (once $10^{4} \mathrm{cfu} / \mathrm{ml}$, twice $10^{3} \mathrm{cfu} / \mathrm{ml}$ ) and in one case with $E$. coli $\left(10^{2} \mathrm{cfu} / \mathrm{ml}\right) ; 11$ strains from non-UTI patients; 5 strains presented as monocultures (thrice $10^{4} \mathrm{cfu} /$ $\mathrm{ml}$ and twice $10^{3} \mathrm{cfu} / \mathrm{ml}$ ) and in 6 cases another species was found in addition (twice $E$. coli $10^{3} \mathrm{cfu} / \mathrm{ml}$, twice $E$. faecalis $10^{4} \mathrm{cfu} / \mathrm{ml}$, once $S$. agalactiae $10^{4} \mathrm{cfu} / \mathrm{ml}$ and once S. hemolyticus $10^{3} \mathrm{cfu} / \mathrm{ml}$ ) (Tables 1 and 2).

In one case, two urine samples were taken on the same day in different ways: middle stream urine (MSU) and material directly from the nephrostomy. Both C. coyleae and E. coli were isolated from MSU and only E. coli from the renal pelvis. In the other case, the following organisms were cultured: C. coyleae, Proteus mirabilis, Prevotella spp., Peptococcus asaccharolyticus, Lactobacillus spp., and S. epidermidis from the material obtained by nephrostomy from a patient with pyonephrosis. Three days after antibiotic therapy was started, only P. mirabilis was cultured from the urine obtained from nephrostomy (Table 3).

We analyzed the susceptibility of all strains to antibiotics applied in the treatment of UTI. Susceptibility rate to benzylpenicillin, ciprofloxacin, gentamycin, tetracycline, and vancomycin was $5.1 \%, 43.6 \%, 69.2 \%, 87.2 \%, 100 \%$, respectively (Table 4).

\section{Discussion}

We present the biggest collection of clinical C. coyleae strains in current literature. The pathogenic role of this individual Corynebacterium species in human infections and their mechanisms of pathogenesis remain to be elucidated. There is a clear lack of distinction between colonization and infectious status, and there remains a need for additional clinical studies as well $[6,7]$. The results of studies performed by other researchers show that Corynebacterium species, particularly those taxa found as part of the normal microflora, are prominent contaminants of clinical materials, although occasionally it is difficult to correctly decide if presence of such bacteria implies contamination or has clinical relevance. If Corynebacterium spp. are recovered from urine specimen as the only bacterial species encountered with a titer of $>10^{4} \mathrm{cfu} /$ $\mathrm{ml}$ or if it is the predominant organism recovered $\left(\geq 10^{5} \mathrm{cfu} /\right.$ $\mathrm{ml}$ ), it is recommended to identify the isolate to the species level [6]. In Table 5, we present recovery of $C$. coyleae isolates from the genitourinary tract of women and men and their clinical significance as demonstrated by various authors. In addition, Fernández-Natal et al. [2] reported $C$. coyleae isolates from cases of sepsis, soft tissue infection, and posttransfusion bacteremia, which in vitro were susceptible to beta-lactams, gentamicin, rifampin, tetracycline, vancomycin, and linezolid, and resistant to clindamycin (Table 4). Resistance to erythromycin occurred in $83.3 \%$ of isolates, all of them presented phenotypic cMLS and harbored the gene ermX. Ortiz-Perez et al. [8] also detected ermX in 8/12 strains. The most concerning fact is that a large percentage of our strains is resistant to ciprofloxacin. We agree that the empirical use of quinolones should not be recommended, and clinically relevant Corynebacterium species always require antimicrobial susceptibility testing [5].

Contamination of a urine sample can contribute to underor over-diagnosis of bacteriuria. In case that C. coyleae is a part of the normal microflora, it can potentially contribute to the implementation of unnecessary antimicrobial therapy [7]. In cases when the presence of $C$. coyleae in urine from a
Table 4 Antimicrobial susceptibility of C. coyleae isolates
Antibiotic susceptibility of C. coyleae isolates

\begin{tabular}{llllll}
\hline & Benzylpenicillin & Ciprofloxacin & Gentamycin & Tetracycline & Vancomycin \\
\hline Our study $(n=39)$ & $5.1 \%$ & $43.6 \%$ & $69.2 \%$ & $87.2 \%$ & $100 \%$ \\
$\begin{array}{l}\text { Fernandez et al. [2] } \\
(n=12)\end{array}$ & $8.3 \%$ & $83.3 \%$ & $100 \%$ & $100 \%$ & $100 \%$ \\
\hline
\end{tabular}


Table 5 Literature review on C. coyleae isolations from genitourinary tract and their clinical significance

Literature Clinical significance

Funke et al. (1997) [1]

Verhelst et al. (2006) [9]

Turk et al. (2007) [10]

Pearce et al. (2014) [11]

Yang (2015) [12]

Brubaker et al. (2016) [13]

Schwaderer et al. (2017) [14]

Barberis et al. (2018) [5]
Females with overactive bladder syndrome

C. coyleae occurred in $0.2 \%$ of vaginal microflora samples of healthy women (with grade 1 of Gram stain vaginal smears)

C. coyleae occurred in the semen of men with prostatitis with severe (> 1 million $\mathrm{WBC} / \mathrm{ml}$ semen) and moderate $(0.2-1$ milion $\mathrm{WBC} / \mathrm{ml}$ semen) inflammation as well as in semen from controls

C. coyleae was most frequently cultured from urine samples from women with urgency urinary incontinence (UUI) than healthy controls

Occurrence in vaginal microflora across gestation in pregnant women treated with placebo or probiotics

The statistical association between UUI symptoms and C. coyleae was demonstrated Urine from women with urinary tract stones

Total nephrectomy following C. coyleae UTI in 36-year-old woman with a history of chronic kidney failure under hemodialysis due to polycystic kidney disease, with several episodes of UTI patient with UTI symptoms is accompanied by more commonly occurring pathogens (for example E. coli, Enterococcus spp., S. saprophyticus or Proteus spp.), it might be considered as contamination. However, if it comes to isolation of $C$. coyleae in quantities of $10^{4} \mathrm{cfu} / \mathrm{ml}$ or $10^{5} \mathrm{cfu} / \mathrm{ml}$, the interpretation might be difficult, especially if the isolate is resistant to commonly prescribed antibiotics.

Based on the new findings presented here and the prior data published by others, $C$. coyleae is a rarely isolated species that should still be considered a pathogen that can be involved in complicated urinary tract infections, mostly in women. Isolation of $C$. coyleae may require confirmation by urinary tract punctuate to exclude contamination. Further studies on the role of $C$. coyleae in UTI are needed.

Open Access This article is distributed under the terms of the Creative Commons Attribution 4.0 International License (http:// creativecommons.org/licenses/by/4.0/), which permits unrestricted use, distribution, and reproduction in any medium, provided you give appropriate credit to the original author(s) and the source, provide a link to the Creative Commons license, and indicate if changes were made.

\section{References}

1. Funke G, Ramos CP, Collins MD (1997) Corynebacterium coyleae sp. nov., isolated from human clinical specimens. Int J Syst Bacteriol 47:92-96

2. Fernández-Natal MI, Sáez-Nieto JA, Fernández-Roblas R et al (2008) The isolation of Corynebacterium coyleae from clinical samples: clinical and microbiological data. Eur J Clin Microbiol Infect Dis 27(3):177-184

3. Taguchi M, Nishikawa S, Matsuoka H et al (2006) Pancreatic abscess caused by Corynebacterium coyleae mimicking malignant neoplasm. Pancreas 33:425-429

4. Duztas O, Erdem H, Pahsa A et al (2006) Epidemiology of corynebacterial urinary infections. IJID 10(3):264. https://doi.org/10. 1016/j.ijid.2005.04.006
5. Barberis CM, Montalvo E, Imas S et al (2018) Total nephrectomy following Corynebacterium coyleae urinary tract infection. JMM Case Rep 5. https://doi.org/10.1099/jmmcr.0.005149

6. Bernard K An update on Corynebacterium species and their clinical significance. Clin Microbiol ASM Portal 2017 Hot Topic. https:// clinmicro.asm.org/index.php/science-skills/training/82-about-asm/ 481-hot-topic-june-2017. Available 12 Feb 2019

7. Bernard K (2012) The genus Corynebacterium and other medically relevant. Coryneform-like bacteria. J Clin Microbiol 50(10):31523158

8. Ortiz-Perez A, Martın-de-Hijas NZ, Esteban J et al (2010) High frequency of macrolide resistance mechanisms in clinical isolates of Corynebacterium species. Microb Drug Resist 16(4). Inc). https://doi.org/10.1089/mdr.2010.0032

9. Verhelst R (2006) Characterization of the vaginal microflora. Dissertation submitted in fulfillment of the requirements for the degree of Doctor in Biomedical Sciences, Faculty of Medicine, University of Ghent

10. Turk S, Korrovits O, Punab M, Mandar R (2007) Coryneform bacteria in semen of chronic prostatitis patients. Int J Androl 30:123128. https://doi.org/10.1111/j.1365-2605.2006.00722.x

11. Pearce MM, Hilt EE, Rosenfeld AB et al (2014) The female urinary microbiome: a comparison of women with and without urgency urinary incontinence. mBio 5(4):e01283-e01214. https://doi.org/ 10.1128/mBio.01283-14

12. Yang S (2015) The role of probiotic Lactobacillus in immune regulation and modulation of the vaginal microbiota during pregnancy. A thesis submitted in conformity with the requirements for the degree of Doctor of Philosophy Department of Physiology University of Toronto (C) Copyright by Siwen Yang

13. Brubaker L, Wolfe AJ (2016) The urinary microbiota: a paradigm shift for bladder disorders? Curr Opin Obstet Gynecol 28(5):407412. https://doi.org/10.1097/GCO.0000000000000298

14. Schwaderer AL, Wolfe AJ (2017) The association between bacteria and urinary stones. Ann Transl Med 5(2):32. https://doi.org/10. 21037/atm.2016.11.73

Publisher's note Springer Nature remains neutral with regard to jurisdictional claims in published maps and institutional affiliations. 